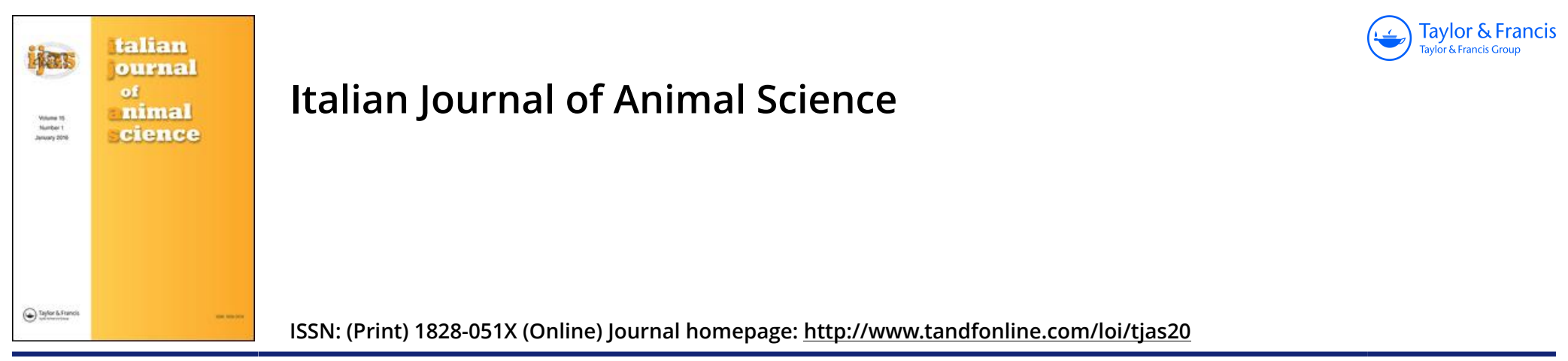

\title{
Biometry traits and geometric morphometrics in sea bass (Dicentrarchus labrax) from different farming systems
}

Francesca Tulli, Ivana Balenovic, Maria Messina \& Emilio Tibaldi

To cite this article: Francesca Tulli, Ivana Balenovic, Maria Messina \& Emilio Tibaldi (2009) Biometry traits and geometric morphometrics in sea bass (Dicentrarchus labrax) from different farming systems, Italian Journal of Animal Science, 8:sup2, 881-883, DOI: 10.4081/ ijas.2009.s2.881

To link to this article: http://dx.doi.org/10.4081/ijas.2009.s2.881

\section{(2) Copyright 2009 Taylor \& Francis Group LLC}

曲 Published online: 07 Mar 2016.

Submit your article to this journal $\pi$

Џ Article views: 36

Q View related articles $\longleftarrow$

4 Citing articles: 1 View citing articles 지 


\title{
Biometry traits and geometric morphometrics in sea bass (Dicentrarchus labrax) from different farming systems
}

\author{
Francesca Tulli, Ivana Balenovic, Maria Messina, Emilio Tibaldi
}

\author{
Dipartimento di Scienze Animali, Università di Udine, Italy
}

Corresponding author: Francesca Tulli. Dipartimento di Scienze Animali. Facoltà di Medicina Veterinaria, Università di Udine. Via S. Mauro 2, 33010 Pagnacco (UD), Italy - Tel. +39 0432650110 - Fax: +39 0432660614

-Email: francesca.tulli@uniud.it

\begin{abstract}
The effect of the farming system on biometry traits and dressing out yield were investigated in market-size European sea bass (Dicentrarchus labrax) cultured extensively or intensively in sea cages or land-based basins. Fish external appearences and shapes were studies with geometric morphometrics in order to assess the potential of combined methodologies in the assessment of finfish quality. Both standard biometry and geometric morphometrics were able to discriminate between sea bass farmed extensively from those cultured under intensive conditions. Geometric morphometrics has been shown to be a valuable tool for describing changes in shape features and could result a useful technique to be associated to biometry traits in the context of fish quality assessment.
\end{abstract}

Key words: Geometric morphometrics, Rearing system, Remote shape analysis, European sea bass.

Introduction - The effect of rearing conditions may have a crucial role in the development of the external morphology of fish resulting in changes of morphometric ratios of fish due to altered stocking densities, swimming capacity, quality and quantity of food (Favaloro and Mazzola, 2003). The shape/ appearance is an important attribute for the consumer and become even more important in the case of fish species of high commercial value like the large size ( $>600 \mathrm{~g}$ ) European sea bass. The aim of the present research was to describe the shape variation of sea bass cultured in different rearing systems based on biometric traits and geometric morphometrics (Bookstein, 1991). The present study is part of a multidisciplinary research funded by the Ministero per le Politiche Agricole e Forestali aiming at characterizing commercial size European sea bass originated from different rearing systems (see Messina et al., 2009; Majolini et al., 2009).

Material and methods - A total of 337 specimens of European sea bass caught between December 2007 and February 2008 were considered. Sea bass originated from 11 commercial farms chosen as representative of the three national major rearing systems (extensive (E), off-shore marine cage (C), inlandbasins (I)). Fish were slaughtered by immersion in ice slurry. 24 hours after slaughter the right side of 91 specimens was filmed using a Canon Powershot 95 digital camera provided with a $50 \mathrm{~mm}$ lens. Seventeen landmarks according to Loy et al. (2000) were digitised onto each image and the $\mathrm{x}$ and y coordinates recorded using IMAGE PRO PLUS 3.0. The coordinates of the fish were analysed together for the rearing system variable by the analysis of the Relative Wraps (by TPSRW 1.16; Rohlf, 1997). The specimens were strictly translated, rotated and rescaled by the least square Procustes method (GLS, Generalised Least-Square superimposition) to obtain the consensus configuration. The individual scores on each correspondence axis were used as the independent variables in a regression on the weight matrix and individuals scored differently on correspondence axes according to particular biometric pattern. This allowed for the visualisation of splines (characteristic shapes) relative to particular rearing system.

Then all the fish were weighed and the following measures were recorded: total and standard length $(\mathrm{cm})$, head length $(\mathrm{cm})$ and maximum height $(\mathrm{cm})$. From linear and weight measurements, morphometric 
indexes, as relative profile (maximum height/total length), cranial index (100 x head length/total length) and condition factor $\left(100 \mathrm{x}\right.$ body weight/total length ${ }^{3}$ ) were calculated. Half of the specimens were dissected and carcass, viscera, liver, gonad, mesenteric fat and fillet (with skin) weight were individually recorded to calculate the relative somatic indices and commercial yield (\% of total weight). The biometric data were analysed according to a monofactorial design (SPSS/PC Release 16.0).

Results and conclusions - After analysing all biometric data gathered at the end of the survey no significant differences were observed in relative profile and condition factor due to the rearing system although significant differences were observed in the cranial index $(\mathrm{P}<0.05)$ (Table 1).

Table 1. Number of individuals, mean weight and morphometric and biometric indices for each rearing system.

\begin{tabular}{|c|c|c|c|c|c|c|}
\hline & & $E_{(n=3)}$ & $C_{(n=3)}$ & $I_{(n=5)}$ & dof & SE \\
\hline n. specimen & & 102 & 97 & 138 & & \\
\hline Body Weight (g) & & $678.7 \pm 197.1$ & $557.4 \pm 146.6$ & $589.8 \pm 170.0$ & & \\
\hline Relative profile & & 0.19 & 0.19 & 0.20 & 334 & 0.738 \\
\hline Cranial Index & & $0.26^{\mathrm{a}}$ & $0.24^{b}$ & $0.24^{b}$ & 334 & 0.002 \\
\hline Condition factor & & 1.24 & 1.17 & 1.19 & 334 & 0.046 \\
\hline $\mathrm{HSI}$ & $(\%)$ & $1.78^{c}$ & $3.20^{\mathrm{a}}$ & $2.28^{b}$ & 142 & 0.552 \\
\hline VSI & $(\%)$ & $9.53^{c}$ & $12.53^{\mathrm{a}}$ & $11.40^{\mathrm{b}}$ & 142 & 6.178 \\
\hline MFI & $(\%)$ & $1.25^{c}$ & $2.20^{\mathrm{b}}$ & $4.23^{\mathrm{a}}$ & 142 & 4.985 \\
\hline Carcass yield & $(\%)$ & $88.59^{a}$ & $85.95^{b}$ & $86.98^{b}$ & 142 & 5.837 \\
\hline Fillet yield & $(\%)$ & $47.21^{b}$ & $48.43^{a}$ & $48.44^{a}$ & 142 & 9.216 \\
\hline
\end{tabular}

$a, b, c p<0.05$.

The biometric indices resulted significantly affected by the rearing system $(\mathrm{P}<0.05)$. Fish reared extensively were characterised by the lowest hepatosomatic (HSI), viscerosomatic (VSI) and mesenteric fat index (MFI) values. They resulted in a higher carcass yield relative to those farmed intensively both in inland-basins and sea cages, $(88.6$ vs. $86.0 \%, \mathrm{P}<0.05)$ while fillet (with skin) yield was higher in fish reared in both the intensive systems ( $48.4 \mathrm{vs.} 47.2 \%, \mathrm{P}<0.05)$. These latter figures appear in the range of value reported in the extensive study on the species of Poli et al., (2001) for similar size fish while the intensive conditions adopted in the farms considered in the present study have negatively affected the carcass yield here registered.

The effect of the rearing system on the shape of sea bass is shown in the scattergram of Figure 1 , where the specimens of the three rearing groups are plotted by relative wrap analysis. The two first relative wraps explained $43.4 \%$ of the total variance. Sea bass originating from the extensive systems were clearly separated from those cultured under the intensive systems. The thin spline grids show the spatial displacement of each landmark along the first Relative Wrap. Fish originating from extensive system resulted in a modification in the head region. This change is determined by a forward displacement of landmarks 15, 16 and 17 . There was a general modification in the dorsal curvature that resulted more pronounced in fish reared in the extensive systems while the intensive reared specimens generally presented an enlarged ventral zone and this could be due to reduced swimming activity, accumulation of perivisceral fat (Table 1) which are quite typical conditions in intensive reared specimens. It is worth to remark that the above changes in morphology were observed during the winter period when fish are naturally subjected to reduced feed consumption and the differences between the two extreme rearing systems are supposed to be reduced. 
This study provides evidence that sea bass shape can be altered under different rearing conditions with a special emphasis on the cranial and ventral regions. Geometric morphometrics has been shown to be a valuable tool for describing changes in shape features and could result a useful technique in the context of fish quality assessment to be associated to biometry traits.

Figure 1. Relative Wrap analysis of 20 specimens of group E, 34 of group C and 37 of group I with the thin plate spline grids showing the shape deformations of commercial size European sea bass. The chart shows the scattergram of the specimens along RW1 and RW2.

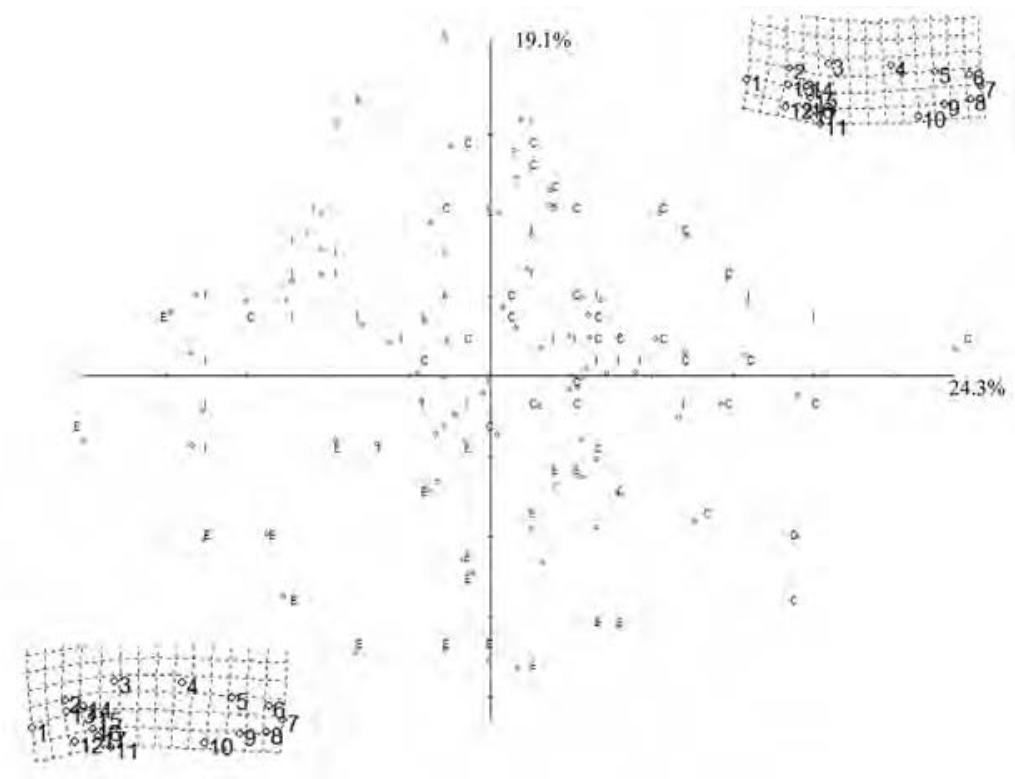

This study was funded by the Ministero delle Politiche Agricole e Forestali, VI Piano triennale della pesca e dell'acquacoltura, Programma "Qualità e Sicurezza alimentare di spigole degli allevamenti nazionali: definizione di indicatori e applicazioni strumentali innovative", Codice Ricerca 6-C-155.

REFERENCES - Bookstein, FL., 1991. Morphometric tool for landmark data. Cambridge University Press, Cambridge. p. 435. Favaloro, E., and Mazzola, A., 2003. Shape change during the growth of sharpsnout seabream reared under different conditions in a fish farm of southern Tyrrenian Sea. Aquaculture engineering 29: 57-63. Loy, A., Boglione, C., Gagliardi, F., Ferrucci, L., Cataudella, S., 2000. Geometric morphometric and internal anatomy in sea bass shape analysis (D. labrax L., Moronidae). Aquaculture 186: 3344. Majolini, D., Trocino, A., Xiccato, G., Santulli, A., 2009. Characterization of European sea bass (D. labrax) from different rearing system by near infrared spectroscopy. It. J. Anim. Sci., in press. Messina, C., Mistretta, G., Conte, L., Tazzoli, M., Santulli, A., 2009. Biochemical and nutritional traits of sea bass (D. labrax) from different rearing systems. It. J. Anim. Sci., in press. Poli, B.M., Parisi, G., Zampacavallo, G., Mecatti, M., Lupi, P., Gualtieri, M., Franci, O., 2001. Quality outline of European sea bass (D. labrax) reared in Italy: shelf life, edible yield, nutritional and dietetic traits. Aquaculture 202: 303-315. Rolf, F.J., 1997. TPSRW - Thin-Plate Spline Relative Wrap Software. Dept. of Ecology and Evolution, State University of New York, Stony Brook, NY, USA. SPSS/PC, Release 16.0, Chicago, IL, USA. 